\title{
MOTIVASI IBU HAMIL DALAM MENGKONSUMSI MAKANAN YANG MENGANDUNG ASAM FOLAT DI DESA KEBONAGUNG KECAMATAN PORONG KABUPATEN SIDOARJO
}

\author{
Lida Khalimatus Sa' diya \\ STIKes Bina Sehat PPNI Mojokerto
}

\begin{abstract}
Folic acid is very important especially in the early days of pregnancy, because at that time the nervous system of a baby is being formed. Folic acid deficiency causes babies born with cleft lip, babies born with low weight, down's syndrome, and miscarriage. The purpose of this study was to determine the motivation of pregnant women to consume folic acid in the Village Kebonagung Porong Sidoarjo. This research is a descriptive study. Population in this study sample of 41 respondents who used as many as 41 respondents drawn with total sampling technique. After the analysis of data collected by the data editing, coding, scoring, tabulating. The results motivate pregnant women to consume folic acid in the Village Kebonagung Porong Sidoarjo in 2013 showed that of the 41 respondents largely motivated weak as many as 20 respondents (48.8\%) and the fraction that is strongly motivated by 8 respondents (19.5\%). Weak motivation is manifested in the form of a weak desire to consume folic acid as part of a much-needed nutrients pregnant women in the developing baby. Motivation studies in pregnant women taking folic acid in the Village Kebonagung Porong Sidoarjo in 2013 showed that of the 41 respondents largely motivated weak. That mothers should increase motivation in consuming foods that contain lots of folic acid for the health of the mother and fetus were conceived.
\end{abstract}

\section{Keywords: Motivation, Pregnancy, Folic Acid}

\section{Pendahuluan}

Asam folat merupakan satu-satunya vitamin yang kebutuhannya selama hamil berlipat dua (Arisman, 2009). Folasin dan folat adalah nama generik sekelompok ikatan yang secara kimiawi dan gizi sama dengan asam folat. Ikatan-ikatan ini berperan sebagai koenzim dalam transportasi pecahan-pecahan karbon-tunggal dalam metabolisme asam amino dan sintesis asam nukleat. Bentuk koenzim ini adalah tetra hidrofolat (Lusa, 2011). Asam folat sangat penting terutama pada masa-masa awal kehamilan, karena pada masa itu sistem saraf bayi sedang terbentuk. Asam folat akan mencegah terjadinya cacat bawaan seperti cacat tabung syaraf (Neural Tube Defects), spina bifida, anenchepaly. Kebanyakan wanita mengkonsumsi folat lebih sedikit dari kebutuhan yaitu $0.2 \mathrm{mg}$ perhari dengan peningkatan 33\% (Kristiyansari, 2010). Kekurangan konsumsi asam folat bisa berdampak lahirnya bayi-bayi cacat yang sudah terbentuk sejak dua sampai empat minggu kehamilan. Cacat ini sudah muncul bahkan sebelum si ibu menyadari dirinya hamil (Asuh Indonesia, 2011). Sering kali para ibu tidak menyadari dirinya kekurangan
Asam Folat karena sebagian besar kehamilan terjadi tanpa direncanakan (Media Indonesia, 2011). Fenomena di Desa Kebonagung Kecamatan Porong Kabupaten Sidoarjo menunjukkan masih banyak ibu hamil yang tidak mengkonsumsi asupan makanan yang mengandung asam folat seperti sayuran hijau, hati, daging dan kacang. Hal ini menyebabkan ibu hamil mengalami kekurangan asam folat dan beresiko mengalami anemia.

Sekitar 24-60\% wanita, baik di negara sedang berkembang maupun yang telah maju, mengalami kekurangan asam folat karena kandungan asam folat di dalam makanan mereka sehari-hari tidak cukup untuk memenuhi kebutuhan ibu hamil (Arisman, 2009). Indonesia sendiri menurut Bowo (2009) belum ada data - data pasti berupa prevalansi adanya penyakit kelainan sumsum tulang belakang. Jumlah angka kematian bayi di Indonesia masih relatif tinggi. Kematian bayi masih belum di identifikasikan penyebabnya karena kekurangan asam folat (Wordpress, 2011). Di Jawa Timur data kematian bayi rata - rata $8 \%$ per tahun dan $30 \%$ diperkirakan disebabkan karena kekurangan asam folat 
(Infokita, 2013). Data Dinkes Kabupaten Sidoarjo tahun 2011 menyebutkan angka kematian bayi yang disebabkan oleh kekurangan asam folat sebesar 20\%. Hasil studi pendahuluan yang dilakukan peneliti pada tanggal 28 November 2012 di Desa Kebonagung Kecamatan Porong Kabupaten Sidoarjo dengan teknik wawancara didapatkan data dari $10 \mathrm{ibu}$ hamil terdapat 7 ibu hamil (70\%) mengatakan jarang mengkonsumsi makanan yang mengandung asam folat seperti brokoli, sayur berdaun hijau: bayam, dan kacang-kacangan, misalnya kacang kering, kacang kedelai. Sedangkan 3 orang (30\%) makanan yang mengadung asam folat.

Salah satu faktor yang mempengaruhi ibu hamil dalam mengkonsumsi asam folat karena kurangnya motivasi dalam mengkonsumsi asam folat. Motivasi itu mempunyai arti dorongan berasal dari bahasa latin movere yang berarti mendorong/menggerakkan. Motivasi inilah yang mendorong seseorang berperilaku beraktifitas dalam pencapaian tujuan (Widayatun, 2010). Motivasi lemah menyebabkan pemenuhan kebutuhan asam folat menjadi kurang. Kekurangan Asam Folat menyebabkan bayi lahir dengan bibir sumbing, bayi lahir dengan berat badan rendah, down's syndrome, dan keguguran. Kelainan lainnya adalah bayi mengalami gangguan buang air besar dan kecil, anak tidak bisa berjalan tegak dan emosi tinggi. Pada anak perempuan, saat dewasa tidak mengalami menstruasi. Pada ibu hamil, kekurang Asam Folat menyebabkan meningkatnya resiko anemia, sehingga ibu mudah lelah, letih, lesu dan pucat (Media Indonesia, 2013).

Bidan sebagai tenaga kesehatan harus mengambil langkah tepat agar ibu hamil bersedia menjaga asupan nutrisi yang mengandung asam folat. Langkah - langkah yang harus dilakukan meliputi melakukan konseling dan penyuluhan. Konseling mengenai semua hal yang berhubungan dengan pentingnya menjaga memenuhi kebutuhan asam folat bagi kehamilannya merupakan salah satu cara agar ibu tetap mengkonsumsi makanan yang mengadung asam folat. Disamping itu penyadaran akan pentingnya motivasi dalam pemenuhan asm folat bagi ibu hamil bisa dilakukan ketika ibu hamil melakukan ANC atau mengunjungi Posyandu.

Tujuan penelitian untuk mengetahui motivasi ibu hamil dalam mengkonsumsi makanan yang mengandung asam folat di Desa Kebonagung Kecamatan Porong Kabupaten Sidoarjo.

\section{Metode}

Penelitian ini menggunakan penelitian deskriptif bertujuan untuk mengetahui Motivasi Ibu Hamil Dalam Mengkonsumsi makanan yang mengandung Asam Folat di Desa Kebonagung Kecamatan Porong Kabupaten Sidoarjo

Populasi dalam penelitian ini adalah seluruh Ibu Hamil di Desa Kebonagung Kecamatan Porong Kabupaten Sidoarjo sebanyak 41 responden.

Teknik sampling yang dipakai adalah total sampling yaitu teknik pengambilan sampel dengan mengambil seluruh anggota populasi dijadikan sampel. Sampel dalam penelitian ini adalah Ibu Hamil di Desa Kebonagung Kecamatan Porong Kabupaten Sidoarjo sebanyak 41 responden.

Variabel dalam penelitian ini adalah Motivasi Ibu Hamil Dalam Mengkonsumsi makanan yang mengandung Asam Folat di Desa Kebonagung Kecamatan Porong Kabupaten Sidoarjo.

Instrumen pengumpulan data pada penelitian ini dengan menggunakan kuesioner skala likert, data dianalisa sesuai jumlah jawaban responden menggunakan tabel distribusi frekuensi dalam bentuk presentasi. Motivasi Kuat (76-100\%), Motivasi sedang (56-75\%), Motivasi Lemah $(\leq 55 \%)$. 
Hasil

Data Umum

Tabel 1. Distribusi Frekuensi Gambaran Usia Responden.

\begin{tabular}{cr|cc}
\hline No & \multicolumn{1}{c}{ Usia } & f & \% \\
\hline $\mathbf{1}$ & $<20$ tahun & 8 & $\mathbf{1 9 . 5}$ \\
$\mathbf{2}$ & 20-35 tahun & 20 & $\mathbf{4 8 . 8}$ \\
$\mathbf{3}$ & $>35$ tahun & 13 & $\mathbf{3 1 . 7}$ \\
& & & \\
\hline & \multicolumn{1}{c}{ Jumlah } & $\mathbf{4 1}$ & $\mathbf{1 0 0}$ \\
\hline
\end{tabular}

Sumber : Data Penunjang

Berdasarkan tabel di atas menunjukkan bahwa dari 41 responden sebagian besar berusia 20-35 tahun yaitu sebanyak 20 responden $(48.8 \%)$.

Tabel 2 Distribusi Frekuensi Pendidikan Responden

\begin{tabular}{clcc}
\hline No & \multicolumn{1}{c}{ Pendidikan } & f & \% \\
\hline 1 & SD/sederajat & 5 & 12.1 \\
2 & SMP/sederajat & 23 & 56.2 \\
3 & SMU/sederajat & 11 & 26.8 \\
4 & Akademi/PT & 2 & 4.9 \\
\hline & Jumlah & 41 & 100
\end{tabular}

Sumber : Data Penunjang

Berdasarkan tabel di atas menunjukkan bahwa dari 41 responden sebagian besar berpendidikan SMP/sederajat sebanyak 23 responden $(56.2 \%)$.

Tabel 3. Distribusi Frekuensi Pekerjaan Responden

\begin{tabular}{llll}
\hline No & Pekerjaan & f & \% \\
\hline $\mathbf{1}$ & Bekerja & 25 & $\mathbf{6 1}$ \\
$\mathbf{2}$ & Tidak bekerja & 16 & $\mathbf{3 9}$ \\
& & & \\
\hline & Jumlah & $\mathbf{4 1}$ & $\mathbf{1 0 0}$ \\
\hline
\end{tabular}

Sumber : Data Penunjang

Hasil penelitian pekerjaan responden menunjukkan bahwa dari 41 responden sebagian besar bekerja yaitu sebanyak 25 responden $(61 \%)$.
Tabel 4 Distribusi Frekuensi Klasifikasi Kehamilan Responden

\begin{tabular}{|c|c|c|c|}
\hline No & $\begin{array}{c}\text { Klasifikasi } \\
\text { Kehamilan } \\
\end{array}$ & $\mathbf{f}$ & $\%$ \\
\hline 1 & Pertama kali & 30 & 73 \\
\hline 2 & $>1$ kali & 11 & 27 \\
\hline & Jumlah & 41 & 100 \\
\hline \multicolumn{4}{|c|}{$\begin{array}{l}\text { Sumber : Data Penunjang } \\
\text { Berdasarkan data di atas menunjukkan } \\
\text { bahwa dari } 41 \text { responden sebagian besar } \\
\text { hamil pertama kali yaitu sebanyak } 30 \\
\text { responden }(73 \%) \text {. }\end{array}$} \\
\hline
\end{tabular}

Data Khusus

Tabel 5 Distribusi Frekuensi Motivasi Ibu Hamil Dalam Mengkonsumsi Makanan Yang Mengandung Asam Folat

Sumber : Data Primer

\begin{tabular}{c|l|cc}
\hline No & $\begin{array}{c}\text { Motivasi Ibu Hamil } \\
\text { Dalam Mengkonsumsi } \\
\text { Asam Folat }\end{array}$ & f & \% \\
\hline $\mathbf{1}$ & Lemah & 20 & $\mathbf{4 8 . 8}$ \\
$\mathbf{2}$ & Sedang & 13 & $\mathbf{3 1 . 7}$ \\
$\mathbf{3}$ & Kuat & 8 & $\mathbf{1 9 . 5}$ \\
\hline & Jumlah & $\mathbf{4 1}$ & $\mathbf{1 0 0}$ \\
\hline
\end{tabular}

Berdasarkan data diatas menunjukkan bahwa dari 41 responden sebagian besar mempunyai motivasi lemah yaitu sebanyak 20 responden (48.8\%) dan sebagian kecil mempunyai motivasi kuat yaitu sebanyak 8 responden $(19.5 \%)$.

\section{Pembahasan}

Penelitian ini membahas tentang motivasi ibu hamil dalam mengkonsumsi makanan yang mengandung asam folat di Desa Kebonagung Kecamatan Porong Kabupaten Sidoarjo tahun 2013. Hasil penelitian menunjukkan bahwa dari 41 responden sebagian besar mempunyai motivasi lemah yaitu sebanyak 20 responden $(48.8 \%)$ dan sebagian kecil mempunyai motivasi kuat yaitu sebanyak 8 responden (19.5\%).

Motivasi itu mempunyai arti dorongan berasal dari bahasa latin movere yang berarti mendorong/menggerakkan. Motivasi inilah yang mendorong seseorang berperilaku beraktifitas dalam pencapaian tujuan (Widayatun, 2010). Istilah motivasi berasal dari kata motif yang dapat diartikan sebagai 
kekuatan yang terdapat dalam diri individu, yang menyebabkan individu tersebut bertindak atau berbuat (Uno, 2010). Motif adalah keadaan dalam pribadi orang yang mendorong individu untuk melakukan aktivitas-aktivitas tertentu guna mencapai sesuatu tujuan. Tiap aktivitas yang dilakukan oleh seseorang itu didorong oleh sesuatu kekuatan dari dalam diri orang itu. Kekuatan pendorong inilah yang kita sebut motif (Suryabrata, 2008). Motivasi menurut Notoatmodjo (2010) motif atau motivasi berasal dari kata Latin moreye yang berarti dorongan dari dalam diri manusia untuk bertindak atau berperilaku. Menurut Walgito (2007) motivasi merupakan keadaan dalam diri individu atau organisme yang mendorong perilaku ke arah tujuan.

Hasil penelitian menunjukkan bahwa sebagian besar responden mempunyai motivasi lemah dalam mengkonsumsi makanan yang mengandung asam folat. Motivasi lemah tersebut terwujud dalam bentuk keinginan yang lemah untuk mengkonsumsi asam folat sebagai bagian dari nutrisi yang sangat dibutuhkan ibu hamil dalam pertumbuhan janin yang dikandungnya. Kurangnya keinginan mengkonsumsi asam folat secara teratur untuk kesehatan bayi. Motivasi lemah responden dalam mengkonsumsi asam folat juga bisa diketahui dari keyakinan yang lemah tentang manfaat asam folat seperti ; lemahnya keyakinan bahwa asupan asam folat bagi janin bermanfaat pembentukan tubuh janin dan lemahnya keyakinan bahwa bahan makanan hewani yang banyak mengandung asam folat terdapat pada hati dan daging. Lemahnya motivasi responden dalam mengkonsumsi asam folat juga bisa dilihat dari lemahnya harapan responden akan manfaat asam folat. Hal tersebut tampak dari lemahnya motivasi mereka untuk bisa menghindari dampak dari kekurangan asam folat yang menyebabkan terhambatnya proses kehamilan dan lemahnya harapan mereka untuk tidak mengalami kekurangan asam folat. Hasil penelitian juga menyebutkan bahwa sebagain kecil responden mempunyai motivasi kuat. Motivasi kuat ini tampak dari hasil kuesioner responden yang terwujud dalam bentuk keinginan kuat untuk mengkonsumsi asam folat sebagai bagian dari nutrisi yang sangat dibutuhkan ibu hamil dalam pertumbuhan janin yang dikandungnya. Kuatnya keinginan untuk selalu mengkonsumsi asam folat secara teratur demi kesehatan bayi. Motivasi kuat responden bisa diketahui dari keyakinan kuat tentang manfaat asam folat seperti ; kuatnya keyakinan bahwa asupan asam folat bagi janin bermanfaat pembentukan tubuh janin dan kuatnya keyakinan bahwa bahan makanan hewani yang banyak mengandung asam folat banyak terdapat pada hati dan daging. Kuatnya motivasi responden dalam mengkonsumsi asam folat juga bisa dilihat dari kuatnya harapan akan manfaat asam folat. Hal tersebut tampak dari kuatnya motivasi mereka dalam menghindari dampak kekurangan asam folat dan kuatnya harapan mereka untuk tidak mengalami kekurangan asam folat.

\section{Simpulan}

Berdasarkan hasil penelitian tentang motivasi ibu hamil dalam mengkonsumsi makanan yang mengandung asam folat di Desa Kebonagung Kecamatan Porong Kabupaten Sidoarjo dapat disimpulkan bahwa sebagian besar mempunyai motivasi lemah.

\section{Saran}

Bagi Responden diharapkan dapat Sebagai bahan informasi kepada ibu hamil trimester 1 tentang pentingnya mengkonsumsi makanan yang mengandung asam folat untuk kesehatan ibu dan janinnya.

Bagi tempat penelitian diharapkan mampu menjadi pedoman untuk lebih meningkatkan pelayanan kesehatan terutama dalam pemberian pendidikan kesehatan dan penyuluhan tentang hal-hal yang berkaitan dengan nutrisi ibu hamil trimester 1 terutama dalam memenuhi kebutuhan asam folat.

Bagi Institusi Kebidanan diharapkan penelitian ini bisa dijadikan literatur untuk mengembangkan wacana keilmuan terutama berkaitan dengan pentingnya mengkonsumsi asam folat bagi kesehatan ibu hamil trimester 1 dan janinnya.

Peneliti selanjutnya diharapkan penelitian ini bisa dijadikan bahan untuk melakukan penelitian selanjutnya dengan cakupan wilayah yang lebih luas dan responden yang lebih banyak. 


\section{DAFTAR PUSTAKA}

Ardian, Agus. (2013). Konsep Motivasi. http://www.medicastore.com/ berita_index/1/index.html. Diakses tanggal 10 Desember 2012.

Arisman. (2007). Gizi Dalam Daur Kehidupan. Jakarta : EGC.

Azwar, Saifuddin. (2008). Penyusunan Skala Psikologi. Yogyakarta : Pustaka Pelajar.

Budiarto, Eko. (2002). Biostatistika. Jakarta : EGC.

Cahyono, M. Dwi Nur. (2013). Kebutuhan Asam Folat Ibu Hamil. http://abhisekabali.wordpress.com/201 3/03/13/kebutuhan-asam-folat-ibuhamil.html. Diakses tanggal 10 Desember 2012.

Gentara, Lukas. (2013). 16 Sumber Vitamin B9 (Asam Folat) Terbaik. http://www.kesehatan.gen22.net/2012/ 10/16-sumber-vitamin-b9-asam-folatterbaik.html. Diakses tanggal 10 Desember 2012.

Hartuti T. (2010). Panduan Ibu Hamil, Melahirkan \& Merawat Bayi. Jakarta : UBA Press.

Hidayat, Aziz Alimul. (2009). Metode Penelitian Kebidanan \& Teknik Analisis Data. Jakarta : Salemba Medika.

Ibrahim, Siti Misaroh, dkk. (2010). Nutrisi Janin dan Ibu Hamil. Yogyakarta : Nuha Medika.

Indriani, Fitria. (2012). Konsep Kehamilan. http://www.scribd.com/doc/5551258 4/konsep-kehamilan.html. Diakses tanggal 10 Desember 2012.

Irwanto. 2013. Tingkatan Motivasi. http//:www.hidayat2.wordpress.com/2 012/06-tingkatan-motivasi.html. Diakses tanggal 10 Desember 2012.

Kristiyanasari, Weni. (2010). Gizi Ibu Hamil. Yogyakarta : Nuha Medika.

Lusa. (2013). Kebutuhan Gizi Ibu Hamil. http//:www.lusa.web.id/category/ ginekologi/kebutuhan-gizi-ibuhamil.html. Diakses tanggal 10 Desember 2012.

Notoatmodjo, Sekidjo. (2003). Ilmu Kesehatan Masyarakat. Jakarta : Rineka Cipta.

Notoatmodjo, Soekidjo. (2010). Metodologi Penelitian Kesehatan. Jakarta : Rineka Cipta.
Nursalam. (2008). Konsep dan Penerapan Metodologi Penelitian Ilmu Keperawatan. Jakarta : Salemba

Uno, Hamzah B. (2010). Teori Motivasi \& Pengukurannya. Jakarta : Bumi Aksara.

Wikipedia. (2013). Asam Folat. http//:www.wikipedia.org/wiki/asam_f olat.html. Diakses tanggal 10 Desember 2012. 